\title{
EVALUATION OF NURSING INFORMATION SYSTEMS USING THE HIS-MONITOR INSTRUMENT: NURSES PERSPECTIVES
}

\author{
Maryam Gholami1, Shahla Damanabi*2(i), Peyman Rezaei Hachesu2 ${ }^{\text {(i) }}$, Fatemeh Sadeghi \\ Ghyassi ${ }^{3}$
}

${ }^{1}$ MSc in Health Information Technology, Department of Health Information Technology, School of Management and Medical Informatics, Tabriz University of Medical Sciences, Tabriz, Iran.

2 Department of Health Information Technology, School of Management and Medical Informatics, Tabriz University of Medical Sciences, Tabriz, Iran.

${ }^{3}$ PhD Candidate of Health information Management, Department of Health Information Technology, School of Management and Medical Informatics, Tabriz University of Medical Sciences, Tabriz, Iran.

\begin{tabular}{ll}
\hline Article Info & A B S T R A C T \\
\hline $\begin{array}{l}\text { Article type: } \\
\text { Research }\end{array}$ & Introduction: \\
\hline Article History: & Introduction: Nurses are one of the largest providers of health and treatment \\
Received: $2019-02-14$ & services in the healthcare setting. A well-designed information system is one \\
Revised: -- & of the necessities for nurses. For this purpose, a proper evaluation of \\
Accepted: $2019-04-08$ & available systems is needed. The aim of this study to evaluate nurses' \\
& perspectives on nursing information systems in hospitals of Tabriz \\
& University of Medical Sciences.
\end{tabular}

* Corresponding author:

Shahla Damanabi

Department of Health Information

Technology, School of Management and Medical Informatics, Tabriz University of Medical Sciences,

Tabriz, Iran.

E-mail: damanabish@tbzmed.ac.ir

\section{Material and Methods:}

This is a cross-sectional study. Two hundred and seventy-five nurses participated in this study. The evaluation instrument was HIS-monitor and 41 specific questions that were related to nurses in four criteria were selected. The validity of the questionnaires was confirmed by experts and the reliability of the instrument was calculated by Cronbach Alpha $(\alpha=0.88)$. Data were analyzed by SPSS Statistics version 16 using descriptive and analytic statistics.

Results:

$50.8 \%$ stated that the studied NIS supports nursing admission process well or very well and $47.7 \%$ believed that these NISs improve access to patientrelated information and documentation of nursing care (48.1\%). 25\% evaluated the function of NIS in the nursing care plan poor or very poor.

\section{Conclusion:}

According to the results, the status of nursing information systems is approximately acceptable and more attention is needed in designing and manufacturing hospital software.

Keywords:

Hospital Information Systems, Computer Systems, Nurses.

How to cite this paper

Gholami M, Damanabi S, Rezaei Hachesu P, Sadeghi Ghyassi F. Evaluation of Nursing Information Systems using the HISMonitor Instrument: Nurses Perspectives. Front Health Inform. 2019; 8(1): e9. DOI: 10.30699/fhi.v8i1.178

\section{INTRODUCTION}

Nowadays, implementation of health care without information technology (IT) seems impossible. Welldesigned information systems can support clinical workflow in various ways and lead to a better patient care [1]. On the other hand, inappropriate information system design may have negative effects on efficiency and quality of patient care. Due to the capabilities of current health care systems and because of clinical and legal information needs, nursing leaders are interested in developing electronic health records [2]. Providing effective nursing care has always been depend on the quality of information available to the nurse [ $\underline{3}]$. In recent years, IT has been introduced in many hospitals to support clinical staff in their daily work. Computerbased nursing information systems are being used for this reason. According to Ashtari and colleagues, Nursing Information System (NIS) is part of the health care information system and clinical decision 
making can be promoted by a well-designed nursing process [4]. Despite the benefits of NIS, studies have shown that some of them do not have a proper design and leading to usability problems for users [ $\underline{5}$. The efficient and effective use of a NIS depends on the appropriate designs of these systems and how well they meet nurses' expectations and needs. A poorly designed NIS can complicate the daily routines of nurses, possibly leading to problems related to the acceptance and use of these systems. In order to optimize the use of nursing information systems, the evaluation of information systems is very important. Failure to understanding of the potential benefits of the information system may leads to lack of evaluation [6]. User satisfaction is one of the key elements in a system evaluation. Without user satisfaction, the system may be abandoned. Because of high costs of system designing and purchasing, it is essential to evaluate user satisfaction as one of the important components of NIS. Evaluation of a NIS highlights the nurses' preferences and expectations and leads to design a proper system [7]. Various questionnaires were designed to evaluate of information systems such as CSUQ, IS09241-11, USE IT-model and HIS-Monitor [ $1, \underline{8}-\underline{10}]$. HIS-Monitor specifies the strengths and weaknesses of information processing in a hospital. HIS-Monitor highlights certain HIS problems such as insufficiently supported cross-departmental communication, legibility of drug orders and other paper-based documents, and overall time needed for documentation [1] . Although some questionnaires are appropriate for specific goals or for collecting data from a specific group, HIS-Monitor can be used in various environments with different users. To our knowledge, the HIS-Monitor has not yet been extensively used to evaluate the Nursing information systems. The aim of this study is evaluating the quality of information in the NIS. The study questions are: (1) what are the information needs of the nurses? (2) To what extent does nursing information systems needs meet?

\section{MARTIAL AND METHODS}

This study evaluates nurses' perspectives on nursing information systems in hospitals of Tabriz University of Medical Sciences. Two thousand and seventy five nurses selected to participate in this study. The evaluation instrument was HIS-monitor. HIS-monitor is a screening instrument to describe the quality of a hospital information system (HIS).

HIS-monitor comprises 107 specific questions which we selected 41 specific questions that were related to nurses in four criteria including nursing admission; access to patient related information; creation and update of a nursing care plan; and documentation of nursing care. The validity of the questionnaires was confirmed by experts and reliability of instrument was calculated by Cronbach Alpha $(\alpha=0.88)$. This questionnaire utilizes a 5-point Likert scale ranging from very bad (score 1) to very good (score 5). Data were analyzed by IBM SPSS Statistics version 16 (IBM, Armonk, NY) using descriptive and analytic statistics.

\section{RESULTS}

The response rate was $88 \%(\mathrm{n}=275)$. Of these participants, 91.2\% had a bachelor's degree and $8.2 \%$ had master degree. The majority of nurses (50.2\%) had 5-10 year work experience, while $25.5 \%$ had a work experience between 10-11 years. In addition, for the majority of nurses (61.6\%), the rate of familiarity with a nursing information system was between 5 and 10 years, and for the rest, it was between 10 and 15 years.

Table 1 shows the distribution of nurses' perspectives about function of "nursing admission" in a NIS. The majority of nurses (73.7\%) believed that access to the patient information of their department is easy and quickly (good or very good). More than half of participants (55.3\%) stated that the system does not provide an acceptable support while documenting risk factors and allergies.

The majority of nurses (45.9\%) stated that the possibility of attaching the information of a patient to another patient record in a NIS is rare. They also believed that in a nursing information system, prescriptions are more readable comparing to manual prescriptions (44.7\%), which leads to medication error reduction. Of nurses, $85.5 \%$ stated that access to lab values of patient is easy and quickly (good/very good). In addition to laboratory results, according to the nurses' response, access to radiological findings and prescription information is also easy and good. Most nurses (62.4\%) stated that the system is capable of preventing unauthorized access to patients' clinical information.

Nurses' perspectives of creation and updating a nursing care plan in a NIS are presented in Table 2. Accordingly, nearly half of nurses believed that system supporting for "obtaining an overview on the tasks for patient" and "following standards or guidelines for planned tasks" is average. Also, one third of participants stated that the nursing information system did not provide a necessary support for preventing medication errors.

The results of this study showed that the majority of nurses (59.6\%) responded to a review of two features: "System support in detecting incomplete documentation during patient discharge" and "System support in response to the legal requirements" in relation to the fourth aim, have expressed good, that the Nursing Information System has provided the necessary support in these areas. 
Table 1: Distribution of nurse's perspectives about nursing admission function of Nursing Information Systems

\begin{tabular}{|c|c|c|c|c|c|}
\hline \multirow{2}{*}{$\begin{array}{c}\text { Nursing } \\
\text { admission }\end{array}$} & $\begin{array}{l}\text { Very } \\
\text { good }\end{array}$ & Good & Average & Bad & $\begin{array}{r}\text { Very } \\
\text { bad }\end{array}$ \\
\hline & $\begin{array}{c}\text { No } \\
(\%)\end{array}$ & $\begin{array}{l}\text { No } \\
\text { (\%) }\end{array}$ & $\begin{array}{l}\text { No } \\
\text { (\%) }\end{array}$ & $\begin{array}{c}\text { No } \\
\text { (\%) }\end{array}$ & $\begin{array}{l}\text { No } \\
\text { (\%) }\end{array}$ \\
\hline $\begin{array}{l}\text { Access } \\
\text { information } \\
\text { of the patient } \\
\text { of your } \\
\text { department }\end{array}$ & $\begin{array}{c}3 \\
(1.2)\end{array}$ & $\begin{array}{c}13 \\
(5.1)\end{array}$ & $\begin{array}{c}51 \\
(20.0)\end{array}$ & $\begin{array}{c}138 \\
(54.1)\end{array}$ & $\begin{array}{c}50 \\
(19.6)\end{array}$ \\
\hline $\begin{array}{l}\text { Access } \\
\text { information } \\
\text { of the patient } \\
\text { of other } \\
\text { department }\end{array}$ & $\begin{array}{c}16 \\
(6.3)\end{array}$ & $\begin{array}{c}26 \\
(10.2)\end{array}$ & $\begin{array}{c}76 \\
(29.8)\end{array}$ & $\begin{array}{c}100 \\
(39.2)\end{array}$ & $\begin{array}{c}37 \\
(14.5)\end{array}$ \\
\hline $\begin{array}{l}\text { System } \\
\text { supporting } \\
\text { while } \\
\text { collecting } \\
\text { patient from } \\
\text { your } \\
\text { department } \\
\end{array}$ & $\begin{array}{c}5 \\
(2.0)\end{array}$ & $\begin{array}{c}32 \\
(12.5)\end{array}$ & $\begin{array}{c}86 \\
(33.7)\end{array}$ & $\begin{array}{c}102 \\
(42.7)\end{array}$ & $\begin{array}{c}23 \\
(9.0)\end{array}$ \\
\hline $\begin{array}{l}\text { System } \\
\text { supporting } \\
\text { while } \\
\text { collecting } \\
\text { patient from } \\
\text { other } \\
\text { department }\end{array}$ & $\begin{array}{c}18 \\
(7.1)\end{array}$ & $\begin{array}{c}41 \\
(16.1)\end{array}$ & $\begin{array}{c}90 \\
(35.3)\end{array}$ & $\begin{array}{c}87 \\
34.1)\end{array}$ & $\begin{array}{c}19 \\
(7.5)\end{array}$ \\
\hline $\begin{array}{l}\text { Readability } \\
\text { of anamnesis } \\
\text { data }\end{array}$ & $\begin{array}{c}1 \\
(0.4)\end{array}$ & $\begin{array}{c}18 \\
(7.1)\end{array}$ & $\begin{array}{c}65 \\
(25.5)\end{array}$ & $\begin{array}{c}112 \\
(43.9)\end{array}$ & $\begin{array}{c}59 \\
(23.1)\end{array}$ \\
\hline $\begin{array}{l}\text { System } \\
\text { supporting } \\
\text { while } \\
\text { documenting } \\
\text { the patient } \\
\text { history }\end{array}$ & $\begin{array}{c}6 \\
(2.4)\end{array}$ & $\begin{array}{c}24 \\
(9.4)\end{array}$ & $\begin{array}{c}96 \\
(37.6)\end{array}$ & $\begin{array}{c}102 \\
(42.7)\end{array}$ & $\begin{array}{c}27 \\
(10.6)\end{array}$ \\
\hline Mean & $\begin{array}{c}23 \\
(9.0) \\
\end{array}$ & $\begin{array}{c}118 \\
(46.3) \\
\end{array}$ & $\begin{array}{c}69 \\
(27.1) \\
\end{array}$ & $\begin{array}{c}39 \\
(15.3)\end{array}$ & $\begin{array}{c}5 \\
(2.0) \\
\end{array}$ \\
\hline
\end{tabular}

The mean scores of the nurse's perspectives about four functions of the NISs is presented in Fig 1. The highest satisfaction rate of the nurses with NIS according to the criteria of HIS-Monitor were as the following: Nursing admission (3.37); Access to patient related information (3.32); Documentation of nursing care (3.34) and the most dissatisfaction rate was Creation and update of a nursing care plan with (3.12) Has earned the lowest score.

Table 2: Distribution of nurses' perspectives about creation and update of a nursing care plan in a nursing information systems

\begin{tabular}{|c|c|c|c|c|c|}
\hline \multirow{2}{*}{$\begin{array}{l}\text { Nursing } \\
\text { admission }\end{array}$} & $\begin{array}{l}\text { Very } \\
\text { good }\end{array}$ & good & average & bad & $\begin{array}{r}\text { Very } \\
\text { bad }\end{array}$ \\
\hline & $\begin{array}{l}\text { No } \\
(\%)\end{array}$ & $\begin{array}{l}\text { No } \\
\text { (\%) }\end{array}$ & $\begin{array}{l}\text { No } \\
\text { (\%) }\end{array}$ & $\begin{array}{l}\text { No } \\
\text { (\%) }\end{array}$ & $\begin{array}{l}\text { No } \\
(\%)\end{array}$ \\
\hline $\begin{array}{l}\text { System } \\
\text { supporting } \\
\text { while } \\
\text { creating and } \\
\text { updating care } \\
\text { plan }\end{array}$ & $\begin{array}{c}15 \\
(5.9)\end{array}$ & $\begin{array}{c}44 \\
(17.3)\end{array}$ & $\begin{array}{c}88 \\
(34.5)\end{array}$ & $\begin{array}{c}98 \\
(38.4)\end{array}$ & $\begin{array}{c}10 \\
(3.9)\end{array}$ \\
\hline $\begin{array}{l}\text { Readability of } \\
\text { nursing care } \\
\text { plan }\end{array}$ & $\begin{array}{c}12 \\
(4.7)\end{array}$ & $\begin{array}{c}29 \\
(11.4)\end{array}$ & $\begin{array}{c}96 \\
(37.6)\end{array}$ & $\begin{array}{c}94 \\
(36.9)\end{array}$ & $\begin{array}{c}24 \\
(9.4)\end{array}$ \\
\hline $\begin{array}{l}\text { System } \\
\text { supporting } \\
\text { about } \\
\text { preventing } \\
\text { medication } \\
\text { errors }\end{array}$ & $\begin{array}{c}24 \\
(9.4)\end{array}$ & $\begin{array}{c}55 \\
(21.6)\end{array}$ & $\begin{array}{c}96 \\
(37.6)\end{array}$ & $\begin{array}{c}72 \\
(28.2)\end{array}$ & $\begin{array}{c}7 \\
(2.7)\end{array}$ \\
\hline $\begin{array}{l}\text { System } \\
\text { supporting } \\
\text { about } \\
\text { preventing } \\
\text { unnecessary } \\
\text { double } \\
\text { examinations }\end{array}$ & $\begin{array}{c}13 \\
(5.1)\end{array}$ & $\begin{array}{c}44 \\
(17.3)\end{array}$ & $\begin{array}{c}104 \\
(40.8)\end{array}$ & $\begin{array}{c}82 \\
(32.2)\end{array}$ & $\begin{array}{c}12 \\
(4.7)\end{array}$ \\
\hline $\begin{array}{l}\text { System } \\
\text { supporting to } \\
\text { obtain an } \\
\text { overview on } \\
\text { the tasks for } \\
\text { patient }\end{array}$ & $\begin{array}{c}7 \\
(2.7)\end{array}$ & $\begin{array}{c}28 \\
(11.0)\end{array}$ & $\begin{array}{c}124 \\
(48.6)\end{array}$ & $\begin{array}{c}83 \\
(32.5)\end{array}$ & $\begin{array}{c}13 \\
(5.1)\end{array}$ \\
\hline $\begin{array}{l}\text { System } \\
\text { supporting to } \\
\text { follow } \\
\text { standards or } \\
\text { guidelines for } \\
\text { planned tasks }\end{array}$ & $\begin{array}{c}17 \\
(6.7)\end{array}$ & $\begin{array}{c}37 \\
(14.5)\end{array}$ & $\begin{array}{c}124 \\
(48.6)\end{array}$ & $\begin{array}{c}69 \\
(27.1)\end{array}$ & $\begin{array}{c}8 \\
(3.1)\end{array}$ \\
\hline Mean & 6.8 & 18.2 & 41.3 & 37.6 & 5.5 \\
\hline
\end{tabular}

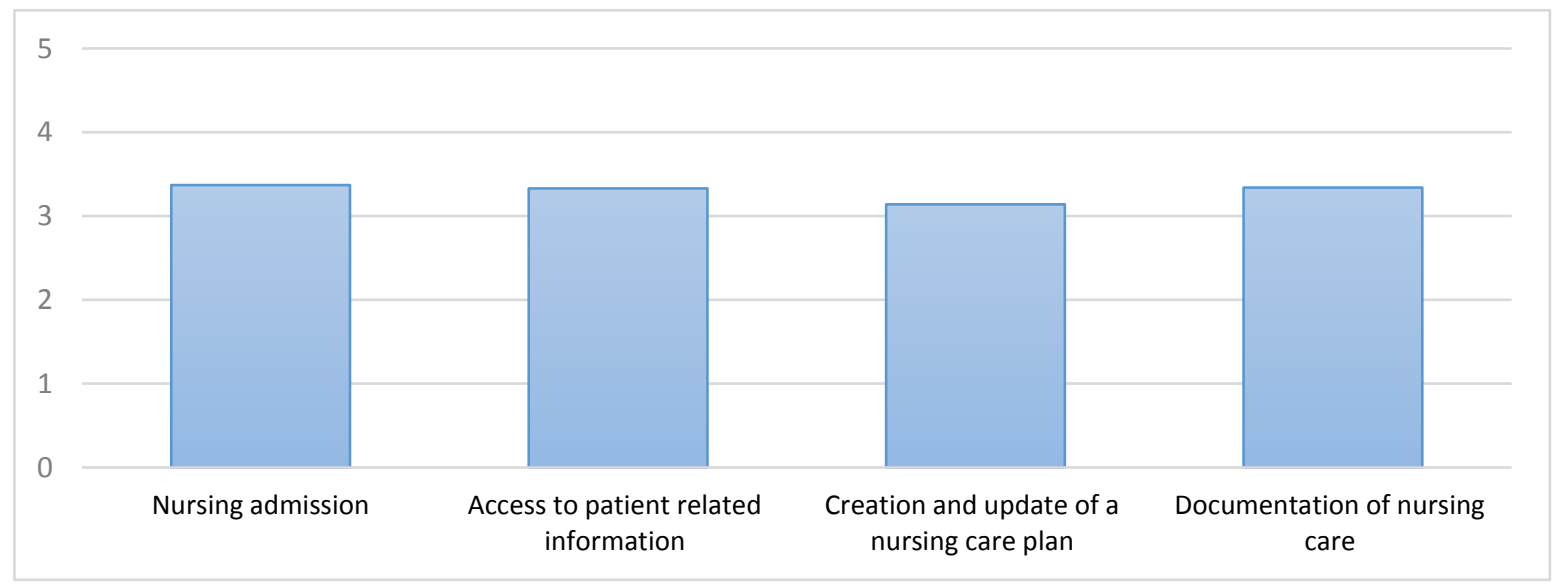

Fig 1: Mean scores of four functions of the nursing information systems from nurses perspectives. 


\section{DISCUSSION}

One of the approaches to assessing hospital information systems is user satisfaction. In general, the user's acceptance seems to reflect the extent to which a system with user attributes (computer knowledge) and task characteristics' (reporting) is consistent? Therefore, user acceptance can be a sufficient indicator of whether an information system supports users in their clinical work processes? [10]. In this study, which was designed to evaluate the perspective of nurses of educational hospitals of Tabriz University of Medical Sciences in relation to nursing information systems, the findings in most cases indicate the relative acceptance of NIS by nurses. The most satisfaction with nursing information system performance in the studied centers was related to the nursing acceptance function and the documentation of nursing practices and the creation and updating of the nursing care plan has the highest percentage of users' dissatisfaction that highest level of disagreement with this function related to system support in providing an overview of the actions taken for a patient and necessary support to prevent drug errors by providing the necessary warnings. In general, the function of creating and updating a nursing care plan in design time of the nursing information system should be considered more.

In relation to first aim is titled 'Nursing admission' $51 \%$ of nurses said it well. The highest percentage of satisfaction related to the features of access to previous patient information of our department (easy and quickly), access to previous patient information from other wards, and the readability of the notes recorded in the system. By increasing the speed of access to patient information the quality of nurses' performance also increases. In a study by Azizzadeh et al., 66\% of nurses said that by having of hospital information systems, the accuracy of the "admission process in the ward and admission of the other ward" has improved [11]. Regarding the subcriteria of Nursing admission' the nurses agreed mainly (73.7\%) on the access information of earlier of the patients of themselves department. This finding is in good agreement with the findings of Kahouei et al in Semnan [12], in which 73\% of nurses were reportedly that the Nursing Information System provided them correct information. George et al found in their study that most employees, due to the availability of a variety of patient information from other departments, had better performance and improved the quality of their clinical decisions [13]. The mast of disagreement among the questions related to the first aim was related to the system supported during the documentation of risk factors and allergies of patient that more than $70 \%$ of nurses had expressed the lack of this feature in the nursing information system which will increase drug mistakes and, as a result, lower quality care. In a study by Khajouei et al, more than 50 percent of nurses expressed that absence of proper alerts contributes to nurses' errors for entering data and wastes their time []‥According to Horsky et al, poor display of alerts increases users' mental efforts and requires spending more time searching for information [14]. In a survey by Jabrailei et al. about evaluation of the quality of the hospital information system service was the lowest score related for reducing medical errors by means of warnings and alarms [15]. So this feature must be considered by nursing managers, when designing systems or purchasing hospital software.

In relation the second aim is titled 'Access to patient related information' most of the nurses described this performance well and about $21.6 \%$ of them did not agree with this system performance. However, the mean score obtained indicates that adequate attention was not paid to access to patient related information that it should be considered when designing the systems. Access and use of reliable health information is the most important factor in the providing of nursing care, so that Killen and colleagues is considered nursing care based on valid health information as one of the essential elements of nurses to provide high quality care [16]. In the current study, nurses had access to a variety of laboratory information, radiology, and prescription drugs. In a study conducted by Eimanei et al, nurses stated that information such as results of tests, dosages and milligrams of medications used, medication and drug codes, the request of the patient's needs, the location of the patient's hospitalization, the medical information, the transfer of patients, date of admission, type of insurance, and previous records of patients are available through the hospital information system and prefer to use this system instead of the traditional system [17], which is consistent with the study before. In Margaret et al study in New Zealand, based on interview results, the Nursing Information System provides better information requirements than medical records due to availability. Also, $50 \%$ of users with the availability of information at any time the places agreed, and 25\% disagreed. This could be due to technical problems [18]. Regarding the sub-criteria of access to patient related information, the nurses agreed mainly that the system prevents unauthorized access to patient clinical data. This indicates the high security of the information system which is an essential requirement for observance of the principle of confidentiality of patient information that refers to the authentication of users before access, as well as the prevention of the access of all unauthorized users. This is consistent with the studies of other researchers $[\underline{15}, \underline{19}]$. 
Among the criteria outlined in HIS-Monitor, the lowest mean score was seen for third purpose titled 'Creation and update of a nursing care plan'. Near $40 \%$ of the nurses did not find their NIS suitable for creation of a nursing care plan, It is a sign of nurses' dissatisfaction. A nursing care plan is a set of activities a nurse performs for the patient and provides a care plan for the patient, which can include diagnosis, features, risk factors, interventions, and expected outcomes, However, the systems studied in this study are not able to display data related care plans , Ahmadi et al. Stated that none of the studied systems in Iran were able to display data related to nursing diagnosis, nursing interventions and expected outcomes or list of goals, and did not support the nursing process [2]. This confirms the results of this survey. In a survey of a question with title how well do you feel supported by the information that is provided to prevent unnecessary double examinations? In relation to the third goal $41 \%$ of respondents said it as moderate that indicates there are no warnings to prevent repetitive testing and financial burden on the patient. In study conducted by Ariaei et al, it is stated that if there is a reminder in the information systems, the amount of forgetfulness in performing many double examinations, which is the responsibility of the night and evening shift nurse in the hospital, is Significant decreases [무] . The mast of disagreement among the questions related to the third aim was related to the system supported while creating and updating a nursing care plan with using care standards that more than $60 \%$ of nurses had expressed the lack of this feature in the nursing information system, this is while Tolabi et al have stated in their study, by optimizing the hospital information system and nurses' access to care standards and their provision based on patient needs, the nurse's relationship with the patient and the care team is improved. Its achievement is the comfort of the patient's imagination, confidence of received care, trust in the nurse, counseling the patient with the nurse, reducing complaints and increasing the satisfaction of the patient and the fellows [21]. This aspect should be addressed in further studies of nursing systems.

In relation to the latest objective of this study titled 'Documentation of nursing care' $48 \%$ of nurses said it well. One of the most valuable tools to gain experience in medical science is to record data. Registering these notes plays an important role in preventing and caring for the patient and improving the relationship between the doctor and other groups that share the care and treatment of the patient. Also, these are legal documents that are registered to describe the course of the disease and the way of treating the disease and are of great importance. Smaradottir et al. conducted a qualitative research entitled "The role of electronics nursing documentation in Continuity of patients Care" In this research, nurses stated that, electronics nursing documentation makes it possible the continuity of care in the process of cardiac catheterization, review of interventions and better access to nursing care information for all sectors of the treatment chain [22]. Smith et al., in a study entitled "Computer Impact in Clinical Documentation "'evaluated the attitude of nurses toward computerization, the time required for documentation, and concluded that due to the high percentage of documentation completed, the quality of nursing charts has improved [23]. In this study, only 40 percent of nurses expected that computerized nursing documentation time saving than manual system, and more than half of them said they spend more time documenting, which wastes their time and reduces the quality of patient care, which has been matched by studies by other researchers, that they all point to an increase in the time of documentation and timely entry of information in the nursing information system $[\underline{3}, \underline{17}$ 24]. In a survey by Ammenwerth et al, nurses have pointed to the standard and uniform of documentation. More than half of the nurses in this study referred to the readability and completeness of the documentation as the most important advantage of the nursing information system [4]. Only 35 percent of nurses in this survey expressed that obtain an overview on the nursing tasks that have been done for a patient is good and more than $50 \%$ of them have described this feature of the nursing information system as unfavorable that Indicates an incomplete record of information, which wastes time and rework in the process of work. Study of Kahui et al confirms the results of this study [25]. Fifty two percent of respondents in this survey expressed that system supported them in corresponds to the legal requirements by nursing documentation is good. In nursing reports regarding care and treatment, it should be clearly stated what, by whom and when? If the nurse's report is not accurate and reliable, the lawmakers are also in doubt and ambiguity in their work and judgment, and therefore the verdict is not trusted. Due to the nursing information system, many manual system problems, including the unreadable of the documentation, accuracy are eliminated, as a result, responses to legal requirements have also improved. These results are consistent with the study of Ahmadi et al that stated the benefits of the nursing information system is identity the requesting person that documented in the system, which has increased responsibility and reduced negligence [26, 27]. Dehgannyeri stated that responsibility and auditing were the experiences most of the participants referred them, according to the experiences of the participants; this system will enhance the audit, the possibility of Wrong tracking, and Individualization [28]. 


\section{CONCLUSION}

The majority of nurses were relatively satisfied with the nursing admission and nursing documentation and the creation and update of a nursing care plan has the highest frequency of users' dissatisfaction. In this study, the sub-set of HIS-Monitor instrument was use. Although the reliability of the modified questionnaire was confirmed ( $\alpha=0.88$ ), the study could benefit from using the original questionnaire to provide a broader picture of NIS issues. The study revealed that current information systems do not have the ability to alert patients' allergic reactions and are weak in preventing medication errors.

According to this study access to laboratory, radiology, and prescription data is appropriate. Due to the results of the study, it can be stated that the status of nursing information systems is not desirable and requires more attention of designers and developers of health information systems. Based on the results, we recommend that Hospital Information System designers interact and Communicate together in order to use the strengths and experiences of each other to improve the quality of hospital information systems and the system should be designed in such a way that don't need for manual documentation, and reduce redundancy in the ward. Nursing care plans, nursing interventions, etc. should be considered in the design of the nursing information system. Nursing name culture and coding books should be used to record nursing diagnoses. Providing online or offline help, and presenting appropriate alerts on the occurrence of an error can improve the design systems.

\section{ACKNOWLEDGEMENTS}

The authors thank the nurses who participated in this study.

\section{AUTHOR'S CONTRIBUTION}

All the authors approved the final version of the manuscript.

\section{CONFLICTS OF INTEREST}

The authors declare no conflicts of interest regarding the publication of this study.

\section{REFERENCES}

1. Ammenwerth E, Ehlers F, Hirsch B, Gratl G. HISmonitor: An approach to assess the quality of information processing in hospitals. Int J Med Inform. 2007; 76(2-3): 216-25. PMID: 16777476 DOI: 10.1016/j.ijmedinf.2006.05.004 [PubMed]

2. Ahmadi M, Habibi Koolaee M. Nursing information systems in Iran. Hakim Health Sys Res. 2010; 13(3): 185-91.

3. Kahooei M, Soleimani M, Ghazavi S, Alaei S. Views, behavior and satisfaction of the nurses and other hospital ward personnel about the effectiveness of computer systems of hospital information on caring process. Health Inf Manage. 2007; 4(2): 193-202.

4. Sadeghi R, Yaghmayi F. Informatics applying in nursing education, research and care. Educ Strategy Med Sci. 2012; 5(3): 199-206.

5. Khajouei R, Abbasi R. Evaluating nurses' satisfaction with two nursing information systems. Comput Inform Nurs. 2017; 35(6): 307-14. PMID: 28060182 DOI: $10.1097 /$ CIN.0000000000000319 [ubMed]

6. Farzandipour M, Meidani Z, Gilasi HR, Dehghan Banadaki R. Ranking of hospital information systems based on requirements of Iran in 2013. Journal of Modern Medical Information Sciences. 2015; 1(1): 19.

7. Michel-Verkerke MB. Information quality of a nursing information system depends on the nurses: A combined quantitative and qualitative evaluation. Int J Med Inform. 2012; 81(10): 662-73. PMID: 22898320 DOI: 10.1016/jijmedinf.2012.07 [ㅁuMed]

8. Iso W. Ergonomic requirements for office work with visual display terminals (VDTs). The International Organization for Standardization. 1998; 45: 9.

9. Lewis JR. IBM computer usability satisfaction questionnaires: psychometric evaluation and instructions for use. International Journal of HumanComputer Interaction. 1995; 7(1): 57-78.

10. Schuring RW, Spil TAM. Relevance and microrelevance for the professionals as determinants of IT diffusion and IT-use in healthcare. In: ERP \& Datawarehousing in organizations: Issues and challenges. Grant G (ed). Hershey: IRM Press; 2003.

11. Ghaderi Nansa L, Piri Z, Salmani E, Gholipour H, Sharghi R. Evaluation of hospital information systems in university hospitals of Tabriz university of medical sciences: Nurses perspectives. Health Inf Manage. 2013; 10(2): 190-200

12. Azizzadeh M, Tofighi S, Fayaz Bakhsh A. Study of nurses' views about the impact of hospital information system on nursing processes in Farabi hospital in Tehran. Payavard. 2014; 8 (3): 235-48.

13. Kahouei M, Babamohamadi H. Factors affecting information technology acceptance in clinical settings from nurses' perspective. Payavard. 2013; 7(4): 26277.

14. Garg AX, Adhikari NK, McDonald H, Rosas-Arellano MP, Devereaux PJ, Beyene J, et al. Effects of computerized clinical decision support systems on practitioner performance and patient outcomes: a systematic review. JAMA. 2005; 293(10): 1223-38. PMID: 15755945 DOI: 10.1001/jama.293.10.1223 [PubMed]

15. Horsky J, Kaufman DR, Oppenheim MI, Patel VL. A framework for analyzing the cognitive complexity of computer-assisted clinical ordering. J Biomed Inform. 2003; 36(1-2): 4-22. PMID: 14552843 [PubMed]

16. Jabraily M, Maleki M, Akbari S, Dehghani M, Salim Amini L. Assessment of hospital information systems 
success in hospitals of Urmia university of medical sciences based on the model adjusted Delone and Mclean . J Urmia Nurs Midwifery Fac. 2015; 12(11): 982-7.

17. Killeen MB, Barnfather JS. A successful teaching strategy for applying evidence-based practice. Nurse Educ. 2005; 30(3): 127-32. PMID: 15900207 [PubMed]

18. Imani E, Khademi Z, Yusefi P, Bahrami Z, Naghizadeh F. Experiences of nursing managers about hospital information system: A qualitative study. Health Management Journal. 2012; 16 (3): 223-32.

19. Piri Z, Damanabi S, Khezri H, Shikhei N. Investigating the functional model EHR security safeguards in the HIS of Tabriz university of medical sciences. J Urmia Nurs Midwifery Fac. 2014; 12(8): 606-12.

20. Ariaei M, Sarafi Nemad A, Kouti J, Mehdipour Z, Bahaadinbeigy K. Role of clinical decision supporting systems in prevention of medical errors from the perspective of health care staff in university hospitals of Kerman university of medical sciences, Iran. Health Inf Manage. 2012; 9(5): 711-23.

21. Tolabi T, Vanaki Z, Memarian R, Namdari M. Quality of nursing documentations in CCU by hospital information system (HIS). Journal of Critical Care Nursing. 2012; 5(2): 53-62.

22. Smáradóttir BF. The role of electronic nursing documentation for continuity of care in short-time wards. [Master Thesis]. University of Tromso; Norway. 2009.

23. Smith K, Smith V, Krugman M, Oman K. Evaluating the impact of computerized clinical documentation. Comput Inform Nurs. 2005; 23(3): 132-8. PMID: 15900170 [PubMed]

24. Munyisia EN, Yu P, Hailey D. Does the introduction of an electronic nursing documentation system in a nursing home reduce time on documentation for the nursing staff?. Int J Med Inform. 2011; 80(11): 782-92. PMID: $21956002 \quad$ DOI: 10.1016/j.ijmedinf.2011.08.009 [PubMed]

25. Ammenwerth E, Rauchegger F, Ehlers F, Hirsch B, Schaubmayr C. Effect of a nursing information system on the quality of information processing in nursing: An evaluation study using the HIS-monitor instrument. Int J Med Inform. 2011; 80(1): 25-38. PMID: $21115392 \quad$ DOI: 10.1016/j.ijmedinf.2010.10.010 [PubMed]

26. Kahouei M, Babamohamadi H. Experiences of nurses in impact of nursing information system on nursing services efficiency. Health Inf Manage. 2013; 10(2): 201-12.

27. Ahmadian L, Ghasemi E, Khajouei R. Evaluating the process of requesting and collecting laboratory test results from nurses' viewpoints before and after HIS implementation . Hakim Health Sys Res. 2014; 17(1): 15-21.

28. Dehghan Nayeri N, Mohammadi Firouzeh M, Seylani K. Nurses' experiences of the hospital information systems. Hayat. 2015; 20(4): 5-18. 